\title{
Student Teachers' Key Learning Experiences - Mapping the Steps for Becoming a Professional Teacher
}

\author{
Elsi Ahonen ${ }^{1}$, Kirsi Pyhältö ${ }^{2}$, Janne Pietarinen ${ }^{3} \&$ Tiina Soini $^{4}$ \\ ${ }^{1}$ Institute of Behavioural Sciences, University of Helsinki, Finland \\ ${ }^{2}$ Faculty of Educational Sciences, University of Oulu; Faculty of Behavioural Sciences, University of Helsinki, \\ Finland \\ ${ }^{3}$ School of Applied Educational Science and Teacher Education, University of Eastern-Finland, Finland \\ ${ }^{4}$ School of Education, University of Tampere, Finland \\ Correspondence: Elsi Ahonen, Institute of Behavioural Sciences, University of Helsinki, Finland. E-mail: \\ elsi.k.ahonen@helsinki.fi
}

Received: December 2, 2014

Accepted: January 14, 2015

Online Published: January 20, 2015

doi:10.5430/ijhe.v4n1p151

URL: http://dx.doi.org/10.5430/ijhe.v4n1p151

\begin{abstract}
Teacher education provides the central forum for student teacher learning. Student teachers are advised to learn about teaching and undergo professional transformation during this instruction. However, research on student teacher learning often focuses on a certain time period and on how students should learn instead of analysing what are the actual key learning experiences of student teachers. In this study, 19 student teachers' interviews are used to analyse key learning experiences during primary teacher education in a large city university's MA programme. The results showed that students undergo several experiences during their studies, and that there are similarities with temporal and contextual location of the incidents and perceived learning outcomes. The results imply that teacher studies entail meaningful, positive and powering learning experiences as well as contradictory and negative learning experiences. Especially, in powering and positive learning experiences student teachers valued pedagogical action that simultaneously promoted their professional beliefs, knowledge and practice. The results also suggest that more attention should be paid to promoting student teachers' active learning during education.
\end{abstract}

Keywords: Student teachers, Teacher education, Key learning experiences

\section{Introduction}

Student teacher learning is key to becoming a skilful teacher, and continuing professional development (Edwards \& Protheroe, 2003). Various pedagogical models such as problem-based learning, project learning and collaborative learning have been introduced (e.g., Tynjälä, 2008; Korthagen \& Lagerwerf, 2001) aiming at facilitating meaningful learning in teacher education and enabling professional learning throughout teaching career. However, the empirical evidence on the effectiveness of the models is scarce (Grossman, 2008; Cochran-Smith \& Zeichner, 2005). Moreover, they often ignore problematic aspects of professional growth (Vermunt \& Endedijk, 2011), such as teacher students' feelings of disengagement or difficulties in learning teaching skills, for example taking pupils' needs into account in the pedagogical situation (Edwards \& D'Arcy, 2004; Edwards \& Protheroe, 2003). Prior research also shows that teacher students are often overly focused on their own performance (Toom, Husu, \& Patrikainen, 2014) rather than on active student learning. There is evidence that especially, early career teachers have a tendency to move away from innovative teaching methods and adopt a more authoritative stance towards their students along with more traditional styles of teaching, during their first years of teaching ( $\mathrm{Ng}$, Nicholas, \& Williams, 2010; Rozelle \& Wilson, 2012). These shortages in the learning to become a teacher may turn problematic deficiencies of future professionalism as a teacher, since the ways in which student teachers perceive and learn to promote their own learning seems to be related to the way they think about educational practices in their own teaching (e.g., Van Petegem \& Donche, 2006).

Prior research on student teacher learning has advanced our understanding of various aspects of teacher learning, such as the development of reflective thinking (Lee, 2005), professional identity (Özmen, 2011; Tang, 2003) and teaching skills (Calderhead \& Shorrock, 1997). Moreover, there is considerable volume of literature on development of teacher knowledge during teacher education. However, there is a gap in the literature on how these complementary 
aspects are experienced by the teacher students throughout their educational path, and in a variety of contexts provided by teacher education (see e.g., van Eekelen, Vermunt, \& Boshuizen, 2006; Edwards \& Protheroe, 2003; Heikkilä, Lonka, Nieminen \& Niemivirta, 2012; Kremer-Hayon \& Tillema, 1999; Tang, 2003; see also Opfer \& Pedder, 2011; Putnam \& Borko, 2000). Furthermore, there is an insufficient understanding of the problematic aspects in becoming professional teacher perceived by the teacher students (Vermunt \& Endedijk, 2011). We argue that in order to better understand and develop more fluent educational path for student teachers we must know more about the steps on the way; when and where the crucial points of professional learning are, and what happens and is actually learned in them. This study aims to mapping the terrain of teacher education and add to the volume of prior literature on student teacher learning by shedding light on the temporal and contextual location of the key learning experiences student teachers undergo during their studies and by analysing the contents and the quality of these experiences.

\subsection{Student teacher learning in teacher education}

Student teacher learning is embedded in various activities provided by teacher education. Students engage in different pedagogical practices while attending lectures, participating in group activities, receiving individual supervision and practice teaching in school. Accordingly, student teachers' learning is dependent on the pedagogical practices of teacher education, and their own engagement in the practices. There is some evidence that student teachers benefit from the kinds of pedagogical practices that facilitate active learning and provide constructive feedback and emotional support (Soini, Pietarinen, Toom, \& Pyhältö, 2014 submitted). For instance, the guidance of experienced mentors who actively facilitate self-regulative learning during teaching practice is shown to be related to high quality, self-directed learning (Perry, Hutchinson, \& Thauberger, 2008). Moreover, constructive relations between teacher educators and student teachers contribute to student teachers' perceived efficacy (Turnbull, 2005). Support from fellow students has also been found to be central for student teacher learning (Michalsky \& Schechter, 2013). However, research shows that teacher education does not always provide an optimal learning environment for active, meaningful learning (Lunenberg \& Korthagen, 2003; Lunenberg, Korthagen, \& Swennen, 2007; Niemi, 2002). Several factors hindering student teacher learning has been identified, including fragmented (e.g., Darling-Hammond 2006) and outdated (e.g., Uusiautti \& Määttä, 2013) curricula of teacher education and distance between "theory and practice" (e.g., Walkington, 2005).

During their studies, student teachers encounter a variety of events that contribute to their learning. These events may be situated in more or less formal settings of teacher education, such as in peer interaction, courses or teaching practice. Some of the events are likely to be more significant than others and have a more profound effect on student teachers' behaviour and thinking; hence, they may be perceived as critical incidents (Tripp, 1993, 2012) or key experiences (Meijer, de Graaf, \& Meirink, 2011). These events or episodes usually occur unexpectedly. The incidents are personally significant and typically include problem-solving resulting in changes in the student teacher's knowledge base, for example in their pedagogical content knowledge or pedagogical practical knowledge (e.g., Shulman, 1987; Shulman, 1998; Shulman \& Shulman, 2004) or behaviour. It has been suggested that critical incidents are triggers that can lead to overcoming resistance to change (see e.g., Meijer \& Oolbekkink, 2012). However, such incidents can change students' beliefs, motivation and action either towards or away from meaningful learning. The nature of the critical incidents can also vary; some incidents are perceived as positive and some as negative (Tripp, 1993, 2012). Especially, inspiring learning experiences during the teacher studies are suggested to be important because they are related to high quality learning outcomes (Ketonen \& Lonka, 2012). Positive and negative key learning experiences are also considered to play an important role in student teachers' development of professional identity (Timostsuk \& Ugaste, 2012). In turn, negative experiences are thought to be related to an increased tendency to avoid challenging goals and situations (Heikkilä, Lonka, Nieminen, \& Niemivirta, 2012).

Moreover, research on student teacher learning has shown that students learn a wide range of knowledge and skills during teacher education. Especially, pedagogical content knowledge and pedagogical practical knowledge have been explored (Shulman \& Shulman 2004, Kansanen, 2009). It has been suggested that the relation between theoretical and practical knowledge is complicated and efforts are needed to construct bridges between different kinds of knowledge structures (Shulman, 1998). Moreover, it has been argued that the quality of teacher knowledge reflects on the development of teacher professional identity i.e. how teachers perceive their work and themselves as professionals (see e.g., Beijaard, Meijer, \& Verloop 2004; Özmen, 2011), for example whether a teacher perceives oneself primarily as a subject matter expert or as pedagogical or didactical expert (Beijaard, Verloop, \& Vermunt 2000, see also Beijaard, Meijer, \& Verloop 2004). Also development of reflective thinking among student teachers has been explored. Griffin (2003) showed that reflective and critical thinking skills can be improved by facilitating student reflection on critical incidents. However, there is also evidence that student teachers are not provided 
adequate opportunities for constructing a meaningful and coherent professional knowledge and belief system (Blomberg, 2008). Student teachers are shown to adopt different kinds of, and often contradictory, beliefs from varying learning contexts in teacher education (e.g., different courses). These beliefs are not automatically connected with the prior beliefs (e.g, prior beliefs are not changed, see e.g., Vosniadou, 1994). Therefore, students' conceptual base for teacher's work maybe be fragmented; consequently, in real life situations they may rely on implicit lay theories (i.e. informal common sense explanations) rather than a solid, scientific professional world view. Teachers' perceptions about pupils' and their own learning are found to have a strong impact on teachers' pedagogical practices; however, these perceptions are often fragmented (Bolhuis \& Voeten, 2004).

Teachers' professional identity is based on the core beliefs one has about teaching and being a teacher. These beliefs are continuously formed and reformed through experience. Therefore, professional action and beliefs are intertwined aspects of the developing professional (Walkington, 2005). Different activities in teacher education studies may be more or less important in terms of meaningful professional learning. Teaching practice is suggested to be an important context for student learning (see e.g., Ben-Peretz, 1995). There is some evidence that teaching practice provides a beneficial ground for developing professional skills (e.g., Lee, 2005) and the development of a self-image as a pedagogical professional or someone with a professional identity (Tang, 2003), providing that student teachers are properly supported and supervised during the field experience. It has been suggested that the first year in the university is especially critical for the students' further engagement and the quality of learning outcomes e.g., what kind of knowledge structures are developed (Lähteenoja, 2010). The encounters with university teachers play an important role in the engagement process, yet Lähteenoja (2010) notes that students often lack the opportunities for such encounters.

Different encounters and critical incidents may promote or hinder the student's active role as learners. These incidents may also have an effect on the student teacher's learning paths if these varying course and practice environments shape the student's beliefs and actions and point them in different directions. The present investigation focuses on analysing the key learning experiences student teachers have during their studies.

\section{The aim of the study}

The study's aim was to gain a better understanding of student teachers' key learning experiences, especially in terms of the episodes that have triggered the change in student teachers' professional knowledge and/or practice. Moreover temporal locations and contexts of the personally significant learning experiences are analysed. Finally, the effect of the key learning experiences on the student teachers is assessed. The study aimed to answer the following research questions:

1. What kind of key learning experiences do the student teachers encounter during their studies?

2. How the personally significant experiences are temporally situated during the teacher studies?

3. In which activities and contexts of teacher education are the experiences embedded?

4. What kind of learning outcomes do the experiences facilitate?

\section{Method}

\subsection{Finnish teacher education}

In Finland, teachers in all comprehensive schools must have a Master's degree. Elementary school teachers have a Master's in educational science or educational psychology and they teach in grades 1-6, where pupils are between 7 and 12 years old. The target time for graduation in elementary school teacher education is five years, but many students take longer. Though there are some differences between different university teacher education programmes, the studies (300 credits) typically include: orientation studies such as ICT and language studies ( 25 credits); main subject studies in educational science/educational psychology (140 credits), including 2-3 teaching practice courses in the teacher training schools (20 credits); two minor subject studies such as multidisciplinary studies in subjects and cross-curricular issues taught in comprehensive school (60 credits), and optional minor subject and optional studies (75 credits). Elementary school teachers may also have one or two subjects that they teach in grades 7-9 if they have included these optional subject studies in their education. The case study presented in this article was conducted in one large research-intensive city university in Finland. 


\subsection{Participants}

This study includes data gathered from 19 elementary school student teachers (Female: 14, Male: 5; Age: Min/Max: 23/51 years; Mean: 31 years) who are finishing their teacher studies. The research permissions for the study were obtained from the department and the participants. The participation was on a voluntary basis, and, the participants were given opportunities to withdraw from the study at any point of the process.

The sample was representative of student teachers as a whole in this context in terms of their gender, age and student status. The criteria for selecting the participants were: students' self-estimated time of graduation (within one year); professional orientation (interest in working in the comprehensive school after graduation) and education as a major subject in the teacher education programme. The criteria were set this way to get the participants who were most likely at the end of their studies and represented the majority of Finnish teacher students both in terms of their major and their professional orientation. Some of the students had completed a significant number of ECTS (European credit transfer and accumulation system) credits before entering the education, sometimes in the Open University, while others had just finished their upper-secondary school. The participants also differed from each other in terms of their prior teaching experience. Some had little or no experience, while others had been working as substitute teachers or school assistants for several years. Furthermore, for some of the students, teacher education was their second choice, while others had applied several times to join the degree programme. In terms of age and gender, the sample represented well the whole student teacher population at the Faculty.

\subsection{Data collection}

The student teacher interviews were conducted by using a contextually modified version of the Teachers' Professional Landscape Inventory (Authors, 2010, see Appendix 1). The instrument was chosen to be able to compare the results emerging from different contexts of teacher learning: learning in the school when practising in the profession (Authors, 2014) and during education when learning the profession. The validity of the adapted instrument was tested in four pilot interviews before the data was collected.

At the beginning of the data collection, the first author visited 11 courses that are typically taken at the final stages of the MA studies such master thesis research seminar and advanced methodology studies. Student teachers undertaking these courses were most likely to be at the end of their studies and also easily contacted. The first author presented a short introduction to the study. The students fitting the criteria were recruited on a voluntary basis and they provided their contact information to the researcher. After this, the potential participants were contacted via e-mail or by phone and a time for an interview was arranged.

The semi-structured theme interview included questions on three main themes:

- the student teacher's learning process during teacher education

- the student teacher's beliefs concerning studying in the teacher education programme

- the student teacher's beliefs concerning teachers' work in the school.

In the interview, students were asked to create a visual representation of their whole (approximately 5 years long) study path as they saw it and to identify and mark the positive, promoting key learning experiences and the negative, hindering key events that made a difference in their studies. After this, the students were interviewed based on their visualisations. They were asked: What happened? What did you learn in this situation? What made you change your way of thinking?

In addition, students' background information including age, teaching experience, reasons for choosing a career as a teacher or enrolling in teacher studies and the current state of their studies were explored. In total, the interview contained four background questions about the participants' personal and professional history and 16 questions about their study in the teacher education programme and teachers' work in the school.

Each interview took between 60 and 210 minutes to complete. All interviews were tape-recorded digitally and decoded into text files by the researcher or the trained research assistant.

\subsection{Analysis}

The qualitative content analysis was carried out using an abductive strategy that suggests using the theory-driven approach for organising multiple data-driven codes within the coherent conceptual interpretative framework (e.g., Chamberlain, 2006). The analysis contained four phases (see Figure 1). In the first phase of the analysis, all the text segments in which students described a key learning experience were coded into an exclusive hermeneutic category. Students felt that these experiences were personally significant and they stated that some change took place in their 
knowledge or behaviour (Tripp, 2012). Altogether, the analysis resulted in 203 key learning experiences. At the end of the first phase, the key learning experiences were coded into two categories, positive and negative key learning experiences, based on the quality of the experience and the students' identification of them as such.

Secondly, the timeline analysis was carried out to determine when the experiences had taken place. For some incidents, the exact time could not be ascertained and therefore only 198 of the 203 experiences were included in the timeline analysis.

Thirdly, the key learning experiences were coded according to the primary contexts of the experiences. The analysis resulted in seven primary contexts of key learning experiences: 1) Educational science; 2) Teaching practice; 3) Multidisciplinary studies in subjects (non-optional minor subject studies); 4) Master's and Bachelor's thesis work; 5) Optional subject studies; 6) Informal social relations with peers and educators, and 7) Other (key learning experience occurred in university studies in general, not in some specific and presented contexts)

Finally, the key learning experiences were coded into four exclusive categories according to general meanings given to the experiences or how the experience contributed to student teacher learning, by using a theory-driven approach (see e.g., Glaser \& Strauss, 1995). These four exclusive categories were: 1) Pedagogical practical knowledge; 2) Pedagogical content knowledge; 3) Combination of theory and practice, and 4) Identity.
Phase 1
Phase 2
Phase 3
Phase 4

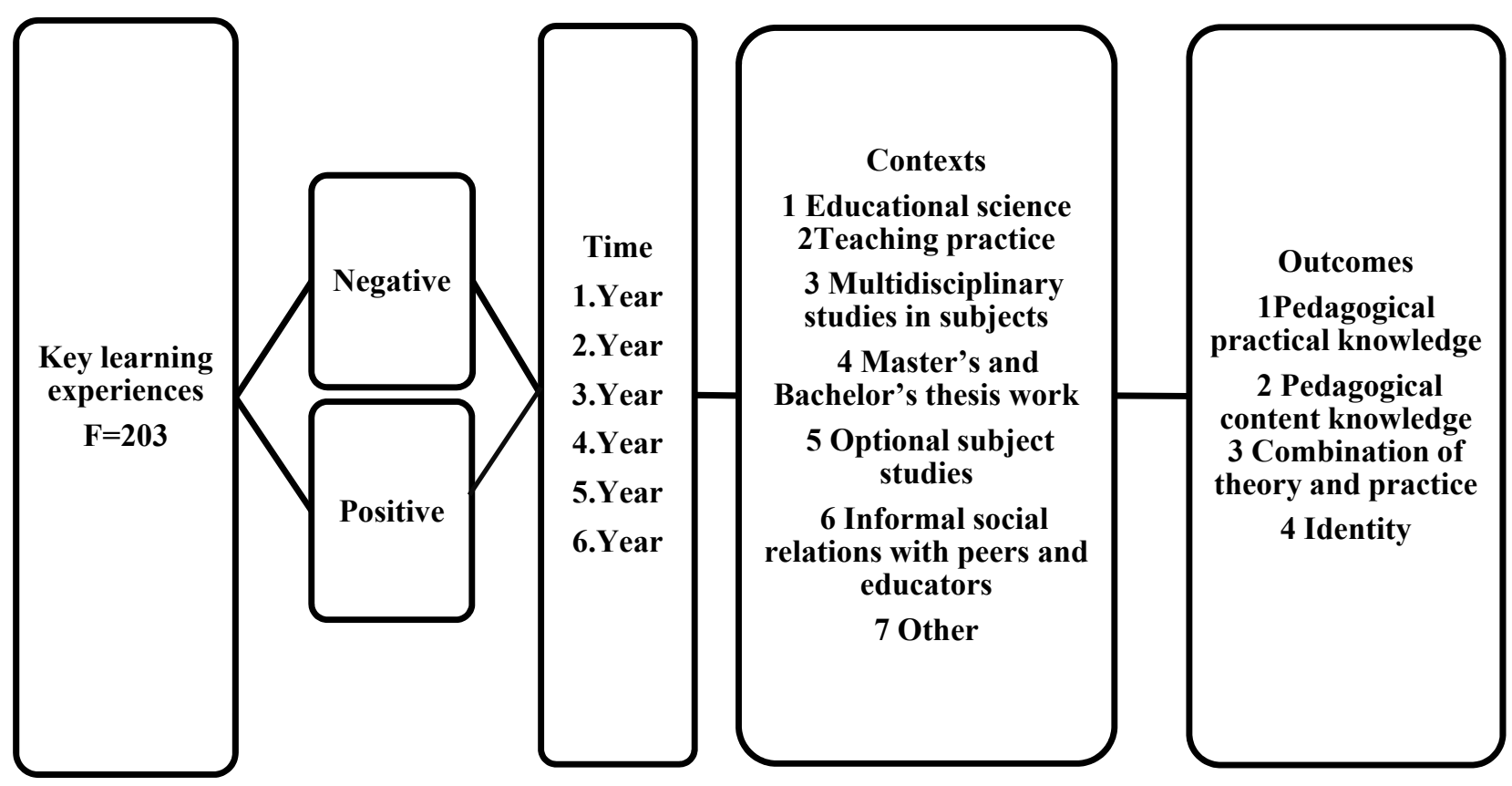

Figure 1. The analysis process

\section{Results}

\subsection{Key learning experiences in student teacher learning}

The students described altogether 203 key learning experiences. Some students recalled over 20 incidents, while others reported only a few learning experiences during their education. The described experiences varied widely. Some experiences had more fundamentally changing impact on student's ways of thinking or behaviour, while others were more or less confirming the existing knowledge structures. Typically student teachers described relatively short terms events that had occurred during some course or in teaching practice, such as standing at the first time in front of the class and seeing oneself as a teacher or getting new pedagogical insights in some specific course. Some 
students also described situations where they themselves participated in pedagogical process that was change making, for example they felt that a lecturer succeeded in engaging students and in challenging their professional thinking. The majority of the learning experiences reported were positive $(75 \%, \mathrm{~F}=153)$, but negative learning experiences were also reported $(25 \%, \mathrm{~F}=50)$. Alignment between the student teachers' expectations and the course contents was characteristic of the positive learning experiences. Students often reported that they had learnt something useful or otherwise important concerning teachers' work. Moreover, positive key learning experiences seldom entailed conflict between student expectations and the opportunities or feedback provided by the environment.

On the other hand, the negative learning experiences typically resulted from destructive friction between the students' situational expectations and the reality of teacher studies such as experiencing a gaping hole between the theory and pedagogical practices carried out in teacher education. Students reported not receiving any practical advice about how to get along with the pupils and their diverse needs. In some cases students recognised the partially fragmented nature of the teacher education programme by criticising the similarity of the contents to be discussed and assignments (e.g., reflective diaries) provided in different courses. In many cases, these negative experiences resulted in strategic distancing from studying instead of active involvement.

Further investigation showed that the key learning experiences varied in terms of the location of students' roles in learning. Two primary forms were identified: key learning experiences resulted from students participating in externally planned and regulated events, such as a course in which a teacher educator set the goals and controlled the teaching-learning process. This typically led to assimilative learning. Students seldom described key learning experiences that resulted from internally and intentionally regulated events, such as actively seeking opportunities to learn and to confront their prior knowledge and beliefs. However, when reported, students typically described engagement in new and innovative learning that significantly promoted their professional development. Such activities entailed actively seeking opportunities to discuss pedagogical dilemmas with teacher educators, or actively engaging in contributing to pedagogical practices in some courses to accomplish learning. These key learning experiences typically involved learning something from oneself (identity) or construction of a more holistic mind-set.

\subsection{The temporal location of the key learning experiences}

Key learning experiences occurred throughout the course of teacher studies. However, the first year was emphasised in students' descriptions. Figure 2 shows that over one third $(\mathrm{F}=78)$ of meaningful learning experiences occurred in the first year. After that, the incidents occurred less frequently every year.

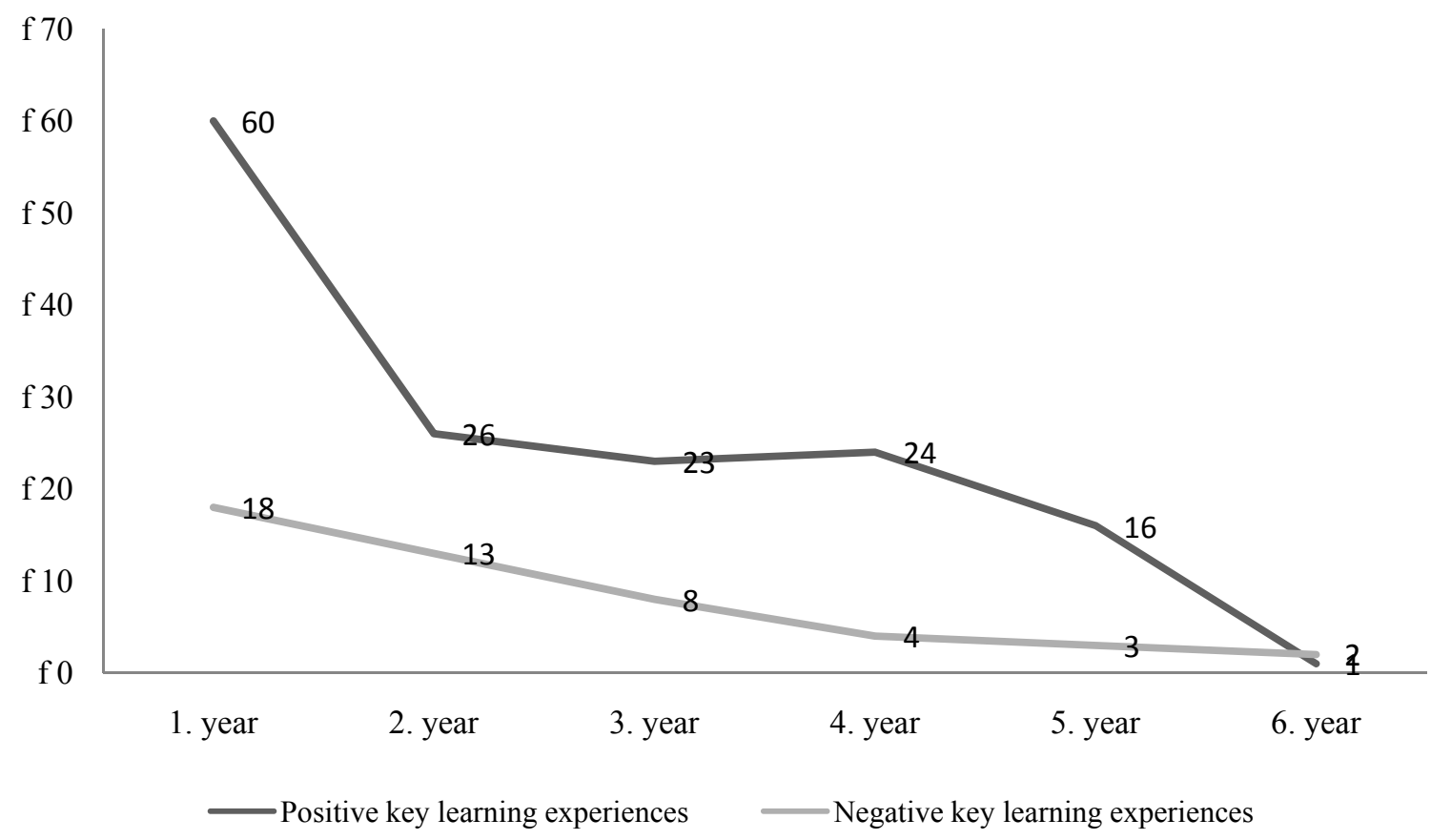

Figure 2. The temporal location of the key learning experiences 


\subsection{Contexts of the key learning experiences}

Further investigation showed that the meaningful learning experiences often took place in similar contexts (see Figure 3.). These incidents were typically situated in non-optional minor subject studies (multidisciplinary studies in subjects) that are carried out in the first and the second year of studies. On the other hand, the theoretical courses of the major subject (Educational science) were rarely identified as a primary context of incidents of learning. However, certain courses were referred to quite frequently and by many students. Students also often identified the teaching practice (at teacher training schools) and the Bachelor's or Master's thesis process as the primary contexts of these experiences. Altogether, 78\% ( $\mathrm{F}=159)$ of incidents reported were situated in these four contexts.

Students less frequently emphasised the importance of volitional courses in their learning. Some students who had the same student group from the beginning of their education stressed the importance of peer interaction (informal social relations). A few students emphasised informal discussions with teacher educators as a primary arena for their learning (informal social relations).

Negative incidents were more likely to be related to non-optional minor subject studies and research studies (the Bachelor's and Master's thesis process) than other contexts. The reasons for this, according to students, were that their expectations were not fulfilled during the non-optional minor subject courses. Within these courses, students often expected to gain useful pedagogical knowledge, but often perceived the courses as too theoretical.

On the other hand, working on a thesis was often perceived as a source of negative experiences when students struggled with self-regulation problems. This involved difficulties with setting goals, keeping to deadlines and completing their work. There were also motivational problems resulting from students' lack of understanding of the reason for research studies when becoming a teacher.

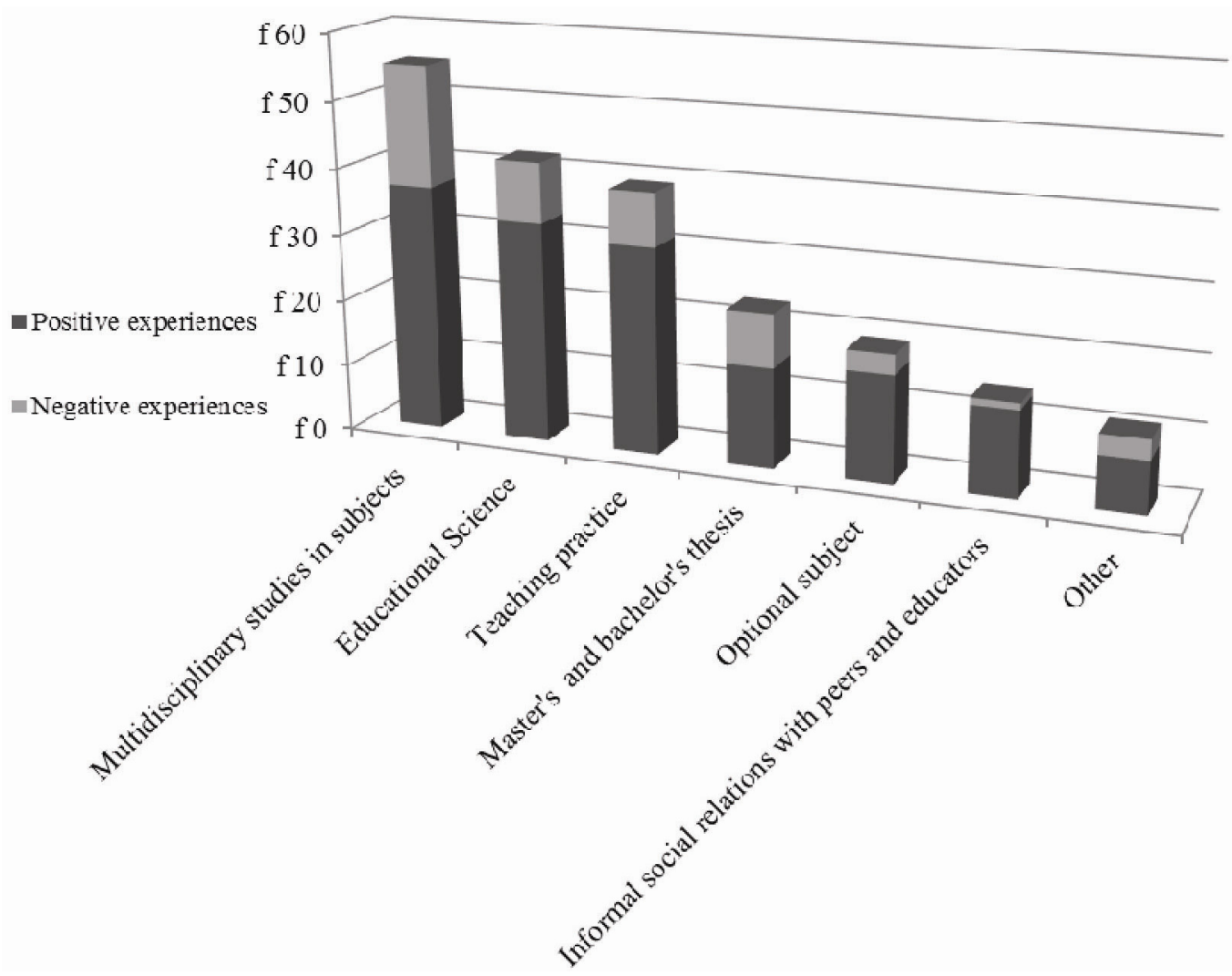

Figure 3. The contexts of key learning experiences 


\subsection{Student teachers' learning outcomes}

The majority of the learning experiences $(54 \%, \mathrm{~F}=111)$ reported concerned a change in student's pedagogical practical knowledge. For instance, students described how they gained a better understanding of how to manage pedagogical situations. This included views on how to do things and what not to do. These kinds of changes in pedagogical practical knowledge were typically experienced in didactic courses and during the teaching practice, where students were able to receive feedback about their performance from their peers, teacher educators or pupils. Student teachers also described the positive and negative experiences in relations and perceptions concerning pedagogy in teacher education. They reflected on the practices of teacher education in both a positive and a negative light. The experiences were also reported to result in changes to their perceptions about and the attitudes towards the practices. These changes were mostly cumulative, in the sense that the new knowledge was added to an already existing knowledge base rather than experienced as a major shift in student teacher thinking and behaviour.

Then there was a course on didactics; it was wonderful and somehow eye opening . . I have always liked mathematics myself, but the pedagogical side of it has always been a bit challenging to think of. For example, how are you able to make things more concrete, plain and understandable? . . . now I feel that when I am going to work in my profession next year, that this (mathematics) is at least one piece of the puzzle that is in shape and balance and to which I can return using the notes I got from this course on didactics. I know that many teachers collect a kind of formal material bank during their studies themselves, but I really have not done that. I haven't got it anywhere else, but from this mathematics course and maybe also from a Finnish language and literature course.

Students also reported changes in pedagogical content knowledge. Altogether $18 \%(\mathrm{~F}=36)$ of students' descriptions concerned a change in theoretical knowledge or general knowledge concerning teachers' work. Student teachers also reported that they had begun to be more conscious about their own way of thinking through reflection. This kind of reflection was typically triggered by discussions and exercises in the theoretical courses. The processes of doing one's own research also triggered these reflections for a few students. This kind of change was mostly cumulative, meaning that new knowledge was added to a pre-existing knowledge base.

In the first didactics course, I felt a bit afraid of how deeply theoretical it was going to be ... Thinking a bit practically, the purpose and meaning of this specific didactics course has become clear to me during these previous advanced courses and from a totally different viewpoint. The course was well structured, but the meaning of it didn't come up back then [during the course]. . . . We reflected on the teacher's professional ethics, other viewpoints and so on ... but it was mostly out of the course book and even though there were some practical things, those were not practised anywhere, but only read from the book ... in this course we were introduced to the didactic triangle . . . the relationship between pupil, teacher and the subject matter ... things that you haven't really thought about before.

Almost as many descriptions $(17 \%, \mathrm{~F}=34)$ concerned change in the student teacher's identity. Students reported that their experiences changed the way they saw themselves as professionals, as students, as learners and as a part of the scholarly community.

Teaching practice was one of the most frequently reported contexts that triggered positive and negative changes in teacher identity and engagement/disengagement in teachers' work in general. Informal discussions with teacher educators were also reported to enhance students' identity as eligible members of the scholarly community. Students typically reflected on the situations in terms of perceived self-efficacy i.e. ability to cope with challenges set by the studies, and in terms of their sense of belonging or lack of it. They may have noted whether they perceived themselves as isolated outsiders or members of the learning community.

The teaching practice in subjects has also been meaningful. ... I don't know if it has affected my perceptions about teacher's work, but I have more perceptions about myself. Somehow it strengthened my self-confidence . . . because before that nobody has ever observed my lessons and then I was able to do it [teach] before these observers . . . the discussions afterwards and the feedback with the supervisors from different subjects were especially beneficial. ... Somehow they were all very good in giving feedback ... we could talk about my weaknesses, but they also gave positive feedback that was very effective. ... [This practice] was very demanding, but somehow I managed it all right

We spent much time with the lecturer. I went to talk about these things with him a lot during his weekly office hours ... and we discussed his school memories... my experiences....and somehow these discussions became even better than the course itself. It was great that I was able to think through these matters with 
someone older and smarter. It was awesome and it made me feel that I was a part of this academic field and my future profession...

Moreover, some students reported that they had learnt to combine theory and practice in the key learning experiences. Eleven percent $(\mathrm{F}=22)$ of the students' descriptions were concerned with combining practical pedagogical knowledge and pedagogical content knowledge. For example, students described situations in teaching practice in which they could identify or apply some theoretical viewpoints studied earlier in their education. This usually happened while planning lessons or afterwards, when reflecting on the lessons with supervising teachers. In these reflections, the students developed more holistic perceptions. Instead of just adding some elements into a pre-existing knowledge base, students described constructing bridges between different knowledge bases: their assumptions, theoretical knowledge, practical knowledge and situations in which this knowledge had been learnt.

those--what do you call them - the methods of collaborative learning . . . in those expertise groups, going back to your base group and using jigsaw teaching methods ... on a practical level and then on a theoretical level - these Vygotsky's ideas and the zone of approximate development, cultural objects of intellectual activity .... and the thing that you find the correct terms for the things (you have sort of recognised before) ... That made me think "Wow!" that even now when you are in some teaching practice course, you think about the group aspects and you about seating plans for pupils and you always reflect on "is this the way to do it if I want them to act in their zone of approximate development, or not . . " or "what is the optimal way to do it and how will I evaluate their performance" ... I think it has been a series of small insights where I have understood that really a teacher cannot just walk into a classroom and pour anything into anyone's head . . . but learning happens despite the teacher and as a result of studying and the teacher affects this process to enhance studying ... and my presumption has been quite the opposite to this thinking since I have always best learnt in the classes where I also liked the teacher

\section{Conclusion}

\subsection{Limitations}

In this study, student teachers' theme interviews, including retrospective storylines, were used to analyse trainee teachers' learning during their teacher education. Certain challenges were involved in using a retrospective approach (e.g. Cox \& Hassard, 2007). Participants' experiences and their overall life situations are often difficult to recall and sum up in a single interview (Kvale, 2007). The student teachers' experiences [as well as their behaviour] are always situated in time, context and their overall life situations, which are often challenging to recall and sum up at the end of the study path. Therefore, retrospection data is also likely to be affected by memory. Accordingly, retrospection would have very likely affected the data, including the generalisation of experiences. However, the reflective and process-oriented design also gave the participants an opportunity to reflect on their study path and identify its significant experiences. This resulted in rich data and ensured that the participants recalled and reported only significant experiences.

Moreover, the data sample represented demographically (age, gender) the student teachers in a large research-intensive university. The student teachers' descriptions also became superfluous in this data. The data reached the point where student teachers' descriptions did not add anything new that could not be attached to already existing categories (see e.g., Onwuegbuzie \& Leech, 2007).

However, just as there are similarities between different teacher education programmes in Finland and abroad, there are also differences between these learning environments. Accordingly, the transferability of the findings should be approached with the caution. However, in terms of personally significant powering learning experiences student teachers emphasised pedagogical action that promoted simultaneously their professional beliefs, knowledge and practice - this pattern of meaningful learning might not be context dependent. This must however be validated by empirical evidence.

\subsection{Findings in light of previous literature}

Our results showed that student teachers encounter several positive and negative learning experiences during their studies. Positive experiences were more frequently reported than negative ones. The results provided new insights by demonstrating how key learning experiences occur during the course of teacher education. The early years in education in particular were emphasised in our data. This particular finding is in line with the results reported in the previous studies concerning academic learning (Lähteenoja, 2010). After the first year, incidents progressively occurred less frequently perhaps because at the beginning of their studies students have more pedagogical courses than in their later years. In the later years, students are also expected to do research and be more self-regulated in 
their learning. Accordingly, our research findings accompany this since student teachers reported that their key learning experiences mostly related to changes in pedagogical practical and pedagogical content knowledge (Shulman, 1987; Shulman, 1998; Shulman \& Shulman, 2004). The most significant questions and object of activities for students, especially at the early phase of the studies, focused on the expansion of their knowledge base in terms of instructional practices, i.e., how to blend and integrate the content and pedagogy in instructional practices.

In our study, teaching practice was emphasised as one of the central contexts of personally significant learning. This is in line with previous suggestions that teaching practice (see e.g., Ben-Peretz, 1995) is one of the most important contexts for student teacher learning. However, student teachers also reported several other contexts where meaningful experiences occurred, some even more frequently than the teaching practice. In our study, non-optional minor subject studies were mostly emphasised as a primary context for learning and the major subject was reported nearly as often as teacher practice as a context for key learning experiences. Negative incidents emerged relatively more often in the non-optional minor subject studies and in the research process (during the Bachelor's and Master's thesis process) than in other contexts. The importance of adopting research-based practices is emphasised in the literature of teaching; however, in our study, student teachers perceived practical pedagogical tips and knowledge to be more central. This confirms previous findings suggesting that student teachers face difficulties in constructing a meaningful and coherent professional belief system during their studies (Authors, 2014, submitted; Blomberg, 2008).

Accordingly, the results showed that most of the students' learning outcomes related to the professional knowledge base and regulation of their own behaviour as a teacher, i.e., pedagogical content knowledge and pedagogical practical knowledge, and further, changes in teacher identity. In a relatively few incidents, the focus was on combining theory and practice. However, integration of theory and practice was often associated with developing more profound understanding about the learners and/or characteristics of meaningful learning. Moreover, our study identified two ways in which the key learning experiences emerged: the experience resulted from internally and intentionally orchestrated student behaviour such as actively seeking and organising opportunities to learn, and from externally orchestrated and regulated activities in which the student was involved. The latter one typically resulted in assimilative learning where new elements were inserted into an existing knowledge base, while the former was characterised by more profound changes in student professional worldviews and identity.

The key learning experiences were often reported to be incidental and to occur unexpectedly, resulting typically assimilative and fragmented learning instead of the construction of a more holistic knowledge base. Especially the negative experiences were often associated with distancing oneself from studying and adopting a more strategic approach to learning. A minority of the key learning experiences entailed changes in students' professional identity as a member of the academic community or as a pedagogical professional. Yet, the learning experiences were perceived personally highly significant. Change in student teacher's professional knowledge both theory and practice typically occurred when there was constructive friction between the challenge provided by the teacher education and learning goals set by the student. Facilitating these kinds of learning experiences within the teacher education is likely to increase student teachers' engagement in learning and development of professional identity. In turn, destructive frictions between the students and their learning environment may result in the non-formation of or a highly fragmented professional identity as well as distancing oneself from studying, carrying out strategic behaviour and disengagement from studying and learning. Therefore, it is crucial that student teachers are provided optimal challenges, opportunities to engage, space to develop their self-regulative capacity in the pedagogical practices, and further, develop their professional identity as a part of the academic community. Firstly, they should develop as peripheral participants, and later on, as core actors in their community of learners (see e.g., Wenger, 1998; Lave \& Wenger, 1991; Rogoff, Matusoff, \& White, 1996).

In conclusion, becoming a professional teacher, in the light of the present findings, is still a challenging process. Future teachers experience that they do not fully succeed in solving the challenges they face in becoming a conceptual and practical professional of a meaningful and active teaching-learning process. The rarity of active learning experienced by students, poses the question of the ability of teacher education to foster students' active agency during their studies and by doing that construct a beneficial ground for teachers to continue their professional development and create meaningful learning environments for themselves and their pupils in the school.

\section{Acknowledgements}

This research is funded by the Academy of Finland (Project: 1259489) and the Finnish Cultural Foundation. 


\section{References}

Authors, (2014 submitted). Becoming a Teacher- Student Teachers' Learning Patterns in Teacher Education. European Journal of Teacher Education.

Authors, (2014). Teachers' professional beliefs about their and pupils' roles in the school. Teacher development, 18 (2),177-197. http://dx.doi.org/10.1080/13664530.2014.900818

Authors, (2010). Pedagogical well-being: Reflecting learning and well-being in teachers' work. Teachers and Teaching: Theory and Practice 16 (6), 765-782. http://dx.doi.org/10.1080/13540602.2010.517690

Ben-Peretz, M. (1995). Curriculum of teacher education programmes. In L.W. Anderson (Eds) International encyclopaedia of teaching and teacher education ( $2^{\text {nd }}$ ed.), 543-547.Oxford: Pergamon.

Beijaard, D., Meijer, P. C., \& Verloop, N. (2004). Reconsidering research on teachers' professional identity. Teaching and Teacher Education, 20, 107-128. http://dx.doi.org/10.1016/j.tate.2003.07.001

Beijaard, D., Verloop, N., \& Vermunt, J. D. (2000). Teachers' perceptions of professional identity: an exploratory study from a personal knowledge perspective. Teaching and Teacher Education, 16, 749-764. http://dx.doi.org/10.1016/s0742-051x(00)00023-8

Blomberg, S. (2008). A Novice Teacher at Comprehensive School. The authentic experiences of teachers beginning their first year of teaching. https://www.doria.fi/bitstream/handle/10024/39665/noviisio.pdf?sequence=1

Bolhuis, S., \& Voeten, M.J.M. (2004). Teachers' conception of student learning and own learning. Teachers and Teaching: theory and practice, 10, 77-98. http://dx.doi.org/10.1080/13540600320000170936

Calderhead, J., \& Shorrock, S.B. (1997). Understanding teacher education. Case studies in the professional development of beginning teachers. London: The Falmer Press

Chamberlain, G.P. (2006). Researching strategy formation process: An abductive methodology. Quality and Quantity 40 (2), 289-301. http://dx.doi.org/10.1007/s11135-005-8094-3

Cochran-Smith, M., \& Zeichner, K.M (Eds.) (2005). Studying teacher education: The report of the panel on research and teacher education. American Educational Research Association/Mahwah, NJ: Erlbaum, Washington, DC. http://dx.doi.org/10.5860/choice.43-2338

Cox, J.W., \& Hassard, J. (2007). Ties to the past in organization research: A comparative analysis of retrospective methods. Organization, 14 (4), 475-497. http://dx.doi.org/10.1177/1350508407078049

Darling-Hammond, L. (2006). Constructing $21^{\text {st }}$-century teacher education. Journal of Teacher Education, 57(3), 300-314. http://dx.doi.org/10.1177/0022487105285962

Edwards, A., \& D A Arcy, C. (2004). Relational agency and disposition in sociocultural accounts of learning to teach. Educational Review, 56 (2), 147-155. http://dx.doi.org/10.1080/0031910410001693236

Edwards, A., \& Protheroe, L. (2003). Learning to see in classrooms: What are student teachers learning about teaching and learning while learning to teach in schools? British Educational Research Journal, 29, 227-242. http://dx.doi.org/10.1080/0141192032000060957

Glaser, B.G. \& Strauss, A. L. (1995). The discovery of grounded theory: Strategies for qualitative research. New Jersey: Transaction publishers.

Griffin, M. L. (2003). Using critical incidents to promote and assess reflective thinking in preservice teachers. Reflective Practice, 4 (2), 207-220. http://dx.doi.org/10.1080/14623940308274

Grossman, P., \& McDonald, M. (2008). Back to the future: Directions for research in teaching and teacher education. American Educational Research Journal, 45(1), 184-205. ～http://dx.doi.org/10.3102/0002831207312906

Heikkilä, A., Lonka, K., Nieminen, J., \& Niemivirta, M. (2012). Relation between teacher students' approaches to learning, cognitive and attributional strategies, well-being, and study success. Higher Education, 64, 455-471. http://dx.doi.org/10.1007/s10734-012-9504-9

Kansanen, P. (2009). Subject-matter didactics as a central knowledge base for teachers, or should it be called pedagogical content knowledge? Pedagogy, Culture \& $\quad$ Society, $17 \quad$ (1), 29-39. http://dx.doi.org/10.1080/14681360902742845

Ketonen, E., \& Lonka, K. (2012). Do situational academic emotions predict academic outcomes in a lecture course? Procedia: Social and Behavioral Sciences, 69, 1901-1910. http://dx.doi.org/10.1016/j.sbspro.2012.12.144 
Korthagen, F. A. J., \& Lagerwerf, B. (2001). Teachers' professional learning: How does it work? In F. A. J. Korthagen, J. Kessels, B. Koster, B. Lagerwerf and T. Wubbels (Eds.), Linking practice and theory, the pedagogy of realistic teacher education. Mahwah: Lawrence Erlbaum Associates, Inc.

Kremer-Hayon, L., \& Tillema, H.H (1999). Self-regulated learning in the context of teacher education. Teaching and Teacher Education 15, 507-522. http://dx.doi.org/10.1016/s0742-051x(99)00008-6

Kvale, S. (2007). Doing Interviews. London: Sage Publications. http://dx.doi.org/10.4135/9781849208963

Lave, E., \& Wenger, J. (1991). Situated learning: legitimate peripheral participation. Cambridge: Cambridge University Press. http://dx.doi.org/10.1017/cbo9780511815355.003

Lee, H.-J. (2005). Understanding and assessing preservice teachers' reflective thinking. Teaching and Teacher Education, 21, 699-715. http://dx.doi.org/10.1016/j.tate.2005.05.007

Lunenberg, M. F., \& Korthagen, F. (2003). Teacher educators and student-directed learning. Teaching and Teacher education 19, 29-44. http://dx.doi.org/10.1016/s0742-051x(02)00092-6

Lunenberg, M., Korthagen, F., \& Swennen, A. (2007). The teacher educator as a role model. Teaching and Teacher Education, 23, 586-601. http://dx.doi.org/10.1016/j.tate.2006.11.001

Lähteenoja, S. (2010). Uusien opiskelijoiden integroituminen yliopistoon : Sosiaalipsykologinennäkökulma. https://helda.helsinki.fi/bitstream/handle/10138/23378/uusienop.pdf?sequence=2 (7.10.2014)

Meijer, P.C., \& Oolbekkink, H. (2012). Positioning defences to learning in the discourse on teachers' professional development. Paper presented at the meeting of EALI's Special Interest Group "Teaching and Teacher Education", Bergen, Norway June 12-14, 2012.

Meijer, P.C., de Graaf, G., \& Meirink, J. (2011). Key experiences in student teachers' development. Teachers and Teaching: Theory and Practice 17(1), 115-129. http://dx.doi.org/10.1080/13540602.2011.538502

Michalsky, T., \& Schechter, C. (2013). Preservice teachers' self-regulated learning: Integrating learning from problems and learning from successes. Teaching and Teacher Education, 30, 60-73. http://dx.doi.org/10.1016/j.tate.2012.10.009

Ng, W., Nicholas, H. \& Williams, A. (2010). School experience influences on pre-service teachers' evolving beliefs about effective teaching. Teaching and Teacher education, 26, 278-289. http://dx.doi.org/10.1016/j.tate.2009.03.010

Niemi, H. (2002). Active learning-a cultural change needed in teacher education and schools. Teaching and Teacher Education, 18 (7), 763-780. http://dx.doi.org/10.1016/s0742-051x(02)00042-2

Onwuegbuzie, A. J., \& Leech, N.L. (2007). A call for qualitative power analyses. Quality \& Quantity: International Journal of Methodology, 41, 105-121. http://dx.doi.org/10.1007/s11135-005-1098-1

Opfer, V. D, \& Pedder, D. (2011). Conteptualizing Teacher Professional Learning. Review of Educational Research 81 (3), 376-407. http://dx.doi.org/10.3102/0034654311413609

Özmen, K.S. (2011). Acting and modelling teacher education: The BEING model for identity development. Turkish online Journal of Qualitative Inquiry 2 (2), 36-50.

Perry, N. E., Hutchinson, L., \& Thauberger, C. (2008). Talking about teaching self-regulated learning: Scaffolding student teachers' development and use of practices that promote self-regulated learning. International Journal of Educational Research, 47, 97-108. http://dx.doi.org/10.1016/j.ijer.2007.11.010

Putnam, R.T., \& Borko H. (2000). What do new views of knowledge and thinking have to say about research on teacher learning? Educational Researcher 29,(1), 4-15. http://dx.doi.org/10.3102/0013189x029001004

Rogoff, B., Matusov, E., \& White, C. (1996). Models of Teaching and Learning: Participation in a Community of Learners. Handbook of education and human development. Oxford, UK: Blackwell.

Rozelle, J. J., \& Wilson, S.M (2012). Opening the black box of field experiences: How cooperating teachers' beliefs and practices shape student teachers' beliefs and practices. Teaching and Teacher Education, 28, 1196-1205. http://dx.doi.org/10.1016/j.tate.2012.07.008

Shulman, L. (1987). Knowledge and Teaching: Foundations of the new reform. Harvard Educational Review, 57 (1), $1-21$. 
Shulman, L. (1998). Theory, Practice and the Education of Professionals. The Elementary School Journal, 98 (5), 511-526. http://dx.doi.org/10.1086/461912

Shulman, L., \& Shulman, J. (2004). How and What Teachers Learn: A Shifting Perspective. Journal of Curriculum Studies, 36(2), 257-271. http://dx.doi.org/10.1080/0022027032000148298

Soini, T., Pietarinen, J., Toom, A. \& Pyhältö, K. (2014 submitted). What contributes to first year student teachers sense of professional agency in the classroom? Teaching and Teachers Theory and Practice

Tang, S. Y. V. (2003). Challenge and support: The dynamics of student teachers' professional learning in the field experience. Teaching and Teacher Education, 19, 483-498. http://dx.doi.org/10.1016/s0742-051x(03)00047-7

Timostsuk, I., \& Ugaste, A. (2012). The role of emotions in student teachers' professional identity. European Journal of teacher Education, 35(4), 421-433. http://dx.doi.org/10.1080/02619768.2012.662637

Toom, A., Husu J. \& Patrikainen, S. (2014). Student teachers' patterns of reflection in the context of teaching practice, European Journal of Teacher Education. http://dx.doi.org/10.1080/02619768.2014.943731

Tripp, D. (1993, 2012). Critical incidents in teaching: The development of professional judgement. London: Routledge. http://dx.doi.org/10.4324/9780203802014

Turnbull, M. (2005). Student teacher professional agency in the practicum. Asia-Pacific Journal of Teacher Education, 33 (2), 195-208. http://dx.doi.org/10.1080/13598660500122116

Tynjälä, P. (2008). Perspectives into learning at the workplace. Educational Research Review, 3, 130-154. http://dx.doi.org/10.1016/j.edurev.2007.12.001

Uusiautti, S. \& Määttä, K. (2013) Significant Trends in the Development of Finnish Teacher Education Programs (1860-2010). Education policy analysis archives, 21(59).

Van Eekelen, I.M., Vermunt, J.D., \& Boshuizen, H. P. A. (2006). Exploring teachers' will to learn. Teaching and Teacher Education, 22, 408-423. http://dx.doi.org/10.1016/j.tate.2005.12.001

Van Petegem, P. \& Donche, V. (2006). Learning environment in higher education: assessing pattern of learning and teaching. In Fisher, Darrell (Ed.). Contemporary approaches to research on learning environments: Worldviews. River Edge, NJ, USA: World Scientific, 93-124. http://dx.doi.org/10.1142/9789812774651_0005

Vermunt, J., \& Endedijk, M. (2011). Patterns in teacher learning in different phases of the professional career. Learning and Individual differences, 21, 294-302. http://dx.doi.org/10.1016/j.lindif.2010.11.019

Vosniadou, S. (1994). Capturing and modeling the process of conceptual change. Learning and Instruction 4 (1), 45-63. http://dx.doi.org/10.1016/0959-4752(94)90018-3

Walkington, J. (2005) Becoming a teacher: encouraging development of teacher identity through reflective practice. Asia-Pacific Journal of Teacher Education, 33(1), 53-64. http://dx.doi.org/10.1080/1359866052000341124

Wenger, E. (1998). Communities of practice: learning, meaning and identity. Cambridge: Cambridge university press. http://dx.doi.org/10.1017/cbo9780511803932 
Appendix 1. Contextually modified version of the Teachers Professional Landscape Inventory (TPLI) instrument.

Intro for the interview

Today we are going to go through your experiences during teacher education and thought regarding teachers work. The interview data will be treated confidentially and only the members of the research group will handle it. Also the identity of the participants will be protected and they can't be identified from the reported results.

The interview is divided into three parts: first I will ask you some background information, then we will discuss about your experiences during teacher education and in the end I would like you to reflect on your future work as a teacher.

\section{$\underline{\text { I I as a teacher and my teaching experience }}$}

1. What kind of teacher qualification you get from your education? Are you studying to become a primary school teacher or a subject teacher?

\section{What made you want to become a teacher?}

3. How much do you currently have experience on teacher's work? Do you have other teaching experience in addition to normative teaching practice? If so, what kind and how much?

\section{Conceptions of your own agency in teacher education}

4. Your will graduate soon. What are your thoughts and how do you feel regarding your studies?

Here interviewees were asked to make a visualisation of their teacher studies on a piece of paper as they saw it; they drew and visualised their journeys as timelines, winding roads or maps. These visualisations were used to support the sharing and discussing of the experiences. Then the participants were asked to identify and mark on their visualisations the key positive, promoting events and the key negative, hindering events that made a difference in their studies. After that, the students were interviewed based on their visualisations. They were asked to describe their experiences one event at a time, and were requested to clarify and elaborate on their descriptions: when and where the key event in question occurred, why they thought it had occurred, and what happened after the event, as well as whether others had contributed to it. We encouraged interviewees to recall what, for them, had been the most significant (e.g. most challenging or inspiring) situations and periods during the studies that may have influenced their learning and development as teachers.

5. Describe and visualise your learning path in teacher education to this paper. The image may be a timeline or other suitable way to describe the study path. Mark the significant events of your study path to the visualisation. The situation may be:

-positive/inspiring or negative/frustrating

-a single encounter with a person or in a longer course / study period, during which you will learn something essential for your future work.

These are support questions for visualisation based interview; each event was recalled by addressing these questions.

- What happened? Can you tell more about the event? Who was there?

- What made the event particularly significant?

- What changed (thought or activity)? What did you think at first, how did your thoughts change after the event? What made you change your thought or actions? How did you feel?

-What essentials did you learn about teachers work and being a teacher? 
- How typical / atypical is the study situation you described? If the situation was atypical, what is the typical learning situation in teacher education?

-In addition to the above-mentioned situations, do you have in mind any longer episodes, that influenced your thoughts of being a teacher or alternatively, situations that in a surprising and quick way impacted your conceptions of being a teacher?

6. Have your thoughts changed during the teacher education? If, how? Would you describe briefly how your thoughts have changed during your study path? What did you think in the beginning of your studies, and what do you think now?

7. How would you describe teacher education from student's perspective? How is the studying here? Describe a typical day of studying and what happens during the day?

8. How do you think that a teacher educator sees the learning environment? What kind of is the everyday work for teacher educators here?

9. How would you describe a typical pedagogical situation in teacher education? What is happening and who is present? What the teacher educator is doing, what the students are doing?

10. What kinds of strengths do you think the teacher education has supported?

11. Is there any kind of challenge / question / issue that wonders you regarding your future work as a teacher? If so, where do you get support to this at the moment?

12. Do you think that teacher education should be further developed? If yes, how? What should be done to reach that aim you just described?

\section{Perceptions about teacher's professional agency in primary school}

13. How is the everyday life in schools in teachers' perspective? Describe a typical work day and what happens during the day.

14. How is the everyday life in schools in pupils' perspective? Describe a typical school day and what happens during the day.

15. You are almost a qualified teacher: What do you consider your core tasks as a teacher? Why? How do you act to achieve your goals and to fulfill your core task?

16. Describe a typical lesson in your future class. What is happening? What the teacher is doing, what the students are doing?

17. How do you see the importance of the professional community for your future work?

18. How would you like a) your pupils b) the parents c) the headmaster and other teachers to describe your working / work with you as a teacher?

19. Do you think that primary schools should be developed further? If yes, to what direction? How would we get into a situation you described?

20. Is there still something you would like to tell me or clarify?

Thank you! 